\title{
Erratum to: Development of the Return-to-Work Obstacles and Self-Efficacy Scale (ROSES) and Validation with Workers Suffering from a Common Mental Disorder or Musculoskeletal Disorder
}

\author{
Marc Corbière $^{1} \cdot$ Alessia Negrini $^{2} \cdot$ Marie-José Durand $^{3} \cdot$ Louise St-Arnaud $^{4}$. \\ Catherine Briand $^{5} \cdot$ Jean-Baptiste Fassier $^{6} \cdot$ Patrick Loisel $^{7} \cdot$ Jean-Philippe Lachance $^{8}$
}

Published online: 12 July 2017

(C) Springer Science+Business Media, LLC 2017

\section{Erratum to: J Occup Rehabil DOI 10.1007/s10926-016-9661-2}

In the original version of this article, the words CMDs and MSDs are interchanged in the abstract section, "Finally, several dimensions of ROSES also predict the participant's RTW within 6 months for MSDs (e.g., job demands), and CMDs (e.g., difficult relation with the immediate supervisor), even when adjusted by several variables (e.g., age,

The online version of the original article can be found under doi:10.1007/s10926-016-9661-2.

Marc Corbière

Corbiere.marc@uqam.ca

Alessia Negrini

Alessia.Negrini@irsst.qc.ca

Marie-José Durand

Marie-Jose.Durand@USherbrooke.ca

Louise St-Arnaud

louise.st-arnaud@fse.ulaval.ca

Catherine Briand

catherine.briand@umontreal.ca

Jean-Baptiste Fassier

jean-baptiste.fassier@univ-lyon1.fr

Patrick Loisel

patrick.loisel@utoronto.ca

Jean-Philippe Lachance

Jean-Philippe.Lachance@usherbrooke.ca

1 Department of Education and Pedagogy, Career Counseling, Université du Québec à Montréal, Centre de recherche de l'Institut Universitaire en Santé Mentale de Montréal (CRIUSMM), 1205, Rue Saint-Denis, Montréal, QC H2X 3R9, Canada severity of symptoms)". The corrected sentence is given below:

Finally, several dimensions of ROSES also predict the participant's RTW within 6 months for CMDs (e.g., job demands), and MSDs (e.g., difficult relation with the immediate supervisor), even when adjusted by several variables (e.g., age, severity of symptoms).

2 Institut de Recherche Robert-Sauvé en Santé et en Sécurité du travail (IRSST), 505 Boulevard de Maisonneuve Ouest, Montréal, QC H3A 3C2, Canada

3 Centre for Action in Work Disability Prevention and Rehabilitation (CAPRIT), School of Rehabilitation, Université de Sherbrooke, 150 Place Charles LeMoyne, Longueuil, QC J4K 0A8, Canada

4 Faculty of Education, Centre de Recherche et d'Intervention sur l'É ducation et la Vie au Travail (CRIEVAT), Université Laval, 2320 Rue des Bibliothèques, Québec, QC G1V 0A6, Canada

5 Faculty of Medicine, School of Rehabilitation, Université de Montréal, 7077, Avenue du Parc, Montréal, QC H3C 3J7, Canada

6 Unité Mixte de Recherche Epidémiologique et de Surveillance Transport Travail Environnement (UMRESTTE), Hospices Civils de Lyon, Université Claude Bernard Lyon 18, Avenue Rockefeller, 69673 Lyon Cedex 08, France

7 Division of Occupational and Environmental Health, Dalla Lana Faculty of Public Health, University of Toronto, 155 College Street, Health Science Building, 6th Floor, Toronto, ON M5T 3M7, Canada

8 School of Rehabilitation, Université de Sherbrooke, CRIUSMM, 150 Place Charles Le Moyne, Bureau 200, Longueuil, QC J4K 0A8, Canada 